\title{
Pharmacovigilance study in medicine department in a tertiary care hospital
}

\author{
Rajat Mishra $^{1}$, Santosh Kumar Jeevangi ${ }^{2}$, Shrenik Vardhamane ${ }^{1}$, Sunil Kumar ${ }^{1}$
}

\begin{abstract}
${ }^{1}$ Department of Pharmacology, All India Institute of Medical Sciences (AIIMS), Patna, Bihar, India

${ }^{2}$ Department of Pharmacology, Mahadeveppa Rampure Medical College (MRMC) Gulbarga

Karnataka, India
\end{abstract}

Received: 23 September 2016

Revised: 25 September 2016

Accepted: 26 October 2016

\section{*Correspondence to: \\ Dr. Rajat Mishra, \\ Email: mishra.rajat13@ \\ gmail.com}

Copyright: (C) the author(s), publisher and licensee Medip Academy. This is an openaccess article distributed under the terms of the Creative Commons Attribution NonCommercial License, which permits unrestricted noncommercial use, distribution, and reproduction in any medium, provided the original work is properly cited.

\begin{abstract}
Background: Adverse drug reactions (ADRs) are major worldwide public health problem. Proper reporting of an ADR is very important as it reduces number of deaths due to ADR and extra financial burden on patients. The aim of the study was to assess the pattern of ADR reporting in outpatients and inpatients of medicine department and to assess their causality, severity and preventability.

Methods: This was a prospective observational study done from April 2013 to June 2014 or in 100 consecutive study subjects (which ever happen first) with ADRs in department of medicine. The clinical pattern, spectrum of ADRs reported and assessment of ADRs in terms of causality, severity and preventability. The causality, severity and preventability assessment was done on the basis of applying various scales for each of them.

Results: A total of 153 suspected ADRs were reported and evaluated from 100 patients. Dermatological system $(28 \%)$ was most commonly involved. Drug class most commonly associated was Antimicrobials (51\%). 68\% ADRs were classified as "Probable" in view of causality, while $68 \%$ were found to be "Moderate" in case of severity. In $65 \%$ of the cases the ADRs was "Probably Preventable". In majority of the cases the suspected drug was withdrawn and alternate therapy was instituted. Most patients recovered from the ADR.70\% of these ADR was Type A.

Conclusions: Awareness about ADR reporting is still poor amongst healthcare professionals in India. Conducting regular training programmes can improve the number of ADR reporting.
\end{abstract}

Keywords: Adverse drug reactions, Causality, Health care professionals, Pharmacovigilance Preventability, Under reporting

\section{INTRODUCTION}

Adverse drug reaction (ADR) is a major worldwide public health problem. It is almost an unavoidable consequence of drug therapy, as no drug is free from unwanted effects. ADR is one of the leading causes of death worldwide.

In developed countries around $3 \%$ to $5 \%$ of hospital admissions are expected to be due to adverse drug reaction and about $10 \%$ of hospitalized patients experience a serious adverse drug reactions. ${ }^{1}$

In India there is a very limited data. An overall incidence of fatal ADRs is $1.8 \% .^{2}$ Minimum of one ADR has been reported to occur in $8 \%$ to $18 \%$ of hospitalized patients. ${ }^{3}$
Pharmacovigilance as defined by the World Health Organization (WHO) is the science and activities relating to the detection, assessment, understanding and prevention of adverse effects or any other possible drugrelated problems.

Detection and assessment of ADRs is of great importance for patient safety profile, as more than $60 \%$ of approved drugs are associated with some type of adverse effects that are not detected prior to their approval for clinical use. $^{4}$

Most of the developed countries have set up an ADR monitoring system at the national level.

Furthermore, reviewing data from different medical, geographic and social population enhances the ability to 
form the basis of new signals which helps in setting up a sound ADR reporting system in the country. ${ }^{[5]}$

ADR in patients can itself present as those that are responsible for hospital admission and those that occur already in admitted patients.

Hospital based ADR monitoring centres can provide very useful information on drug usage. ${ }^{6}$ Management of ADR further adds up financially to an already burdened health care system which is usually preventable. ${ }^{7}$

ADRs reporting are done by various methods but the most commonly applied method is Spontaneous Reporting System (SRS) by Health care professionals (HCP). The main drawback of SRS by HCP is very less number of reporting and also selective reporting. This can lead to false conclusion about drug risk. ${ }^{8,9}$

Therefore, including patients as reporters of ADR may increase its early detection and reporting and provide useful added source of information as patients are found to perceive ADRs more rapidly and clearly, than $\mathrm{HCP} .{ }^{8,9}$ In Indian scenario the whole concept of ADR reporting is still in scarce.

ADRs are of great concern to the general population, HCP, and regulatory bodies. ${ }^{10}$

Not much of an attention has been given so far and only a handful of original studies have been done in this regard. ${ }^{11}$ India rates as low as less than $1 \%$ in Pharmacovigilance reporting when compared to other developed countries reporting of $5 \%$ or more. $^{12}$

We have very few pharmacovigilance centers at present and lots of hard work is needed, to collect ADR reports which may form the basis of safety surveillance of millions of therapeutically active substances either alone or in combinations.

There is a need of establishing ADR monitoring centre at every tertiary care hospital.

\section{METHODS}

This prospective observational study was conducted after obtaining an approval from institutional ethics committee, subjects with suspected ADRs as Outpatients and inpatients in Department of Medicine, Basaveshwar Teaching and General Hospital, Gulbarga were included in the study only after getting their written informed consent. Study period was of 15 months from April 2013 to June 2014 or first 100 consecutive patients which ever happened first.

Before initiation of the study, a training programme on pharmacovigilance was conducted in medicine department for healthcare professionals. Data of spontaneously reported ADRs by healthcare professionals were collected through the ADR reporting form, made available in medicine OPD and wards. All suspected adverse drug reactions that were due to the medications taken by the patients as outpatients and inpatients and age 13 years and more were included in the study. While the use of alternatives medicines like Homeopathy, Unani, Sidda, Ayurveda, over dosage, excess consumption, mentally retarded patients along with patients who were drug addicts and unconscious patients were all excluded from the study.

For each patient with suspected ADR, a detailed history was taken and any untoward event was labelled as adverse drug reaction after discussion with the treating physician.

A through scrutiny of data was done to assess pattern, extent, severity and duration of the reactions, to detect any predisposing or underlying disease/pathological factors, and to assess any other organ/ system involvement as a part of the drug reaction.

The causality of the reactions was assessed by WHO UMC scale, severity of ADR using Adapted Hartwig scale and preventability assessed by using Modified Schumock and Thornton scale. Follow up was done to assess the clinical progress of the cases.

Average cost per patient was calculated by total amount spent on treating ADRs divided by total the number of patients suspected with ADR. For calculating the cost due to ADR per patient included laboratory investigation, specific drugs used to treat ADR and other supportive therapy were all calculated per unit per patient.

\section{Statistical analysis}

The data was analysed using descriptive statistics namely mean and standard deviation for quantitative variables SPSS V13 statistical software was used to generate graphs and tables wherever necessary.

\section{RESULTS}

A total of 153 suspected ADRs were reported and evaluated from 100 patients. Dermatological system (28\%) was most commonly involved. Drug class most commonly associated was Antimicrobials (51\%). 68\% ADRs were classified as "Probable" in view of causality, while $68 \%$ were found to be "Moderate" in case of severity. In $65 \%$ of the cases the ADRs was "Probably Preventable". In majority of the cases the suspected drug was withdrawn and alternate therapy was instituted. Most patients recovered from the ADR.70\% of these ADR was Type A.

\section{DISCUSSION}

During the study period total no of the patients with suspected ADRs were 100. Among those ADRs 
encountered in male patients were $(\mathrm{N}=61)$ when compared to female patients $(\mathrm{N}=39)$. This result was in consistence with the earlier documented study. ${ }^{13}$

As far as age and gender distribution of the patients who encountered adverse drug reactions (ADRs) during the study period were concern, in both males and females maximum ADRs were encountered in age group of 41-60 years $(41 \%)$ followed by $26-40$ years (39\%)in males, in females age group 41-60 years (41\%) followed by $26-40$ years (34\%). However the incidence of ADRs has not increased consistently with age. This observation was in contradiction with the observations of the earlier studies where higher incidences of ADRs have been observed with increasing in age suggesting that increasing age is a risk factor for occurrence of ADRs. ${ }^{14-16}$ However the contradicting result of the present study could be due to lesser number of geriatric patients in the study.

Table 1: Type of patients.

\begin{tabular}{|lllllll|}
\hline Type of patients & Male $\mathbf{n}$ & Male \% & Female $\mathbf{n}$ & Female \% & Total $\mathbf{n}$ & Total \% \\
\hline Outpatient & 35 & 57 & 17 & 44 & 52 & 52 \\
\hline Inpatient & 26 & 43 & 22 & 56 & 48 & 48 \\
\hline Total & 61 & 100 & 39 & 100 & 100 & 100 \\
\hline
\end{tabular}

Table 2: If outpatient than (Adverse drug reaction was the cause for admission).

\begin{tabular}{|lllllll|}
\hline Outpatient than & Male $\mathbf{n}$ & Male \% & Female $\mathbf{n}$ & Female \% & Total $\mathbf{n}$ & Total \% \\
\hline Admitted & 19 & 54 & 5 & 29 & 24 & 46 \\
\hline Not admitted & 16 & 46 & 12 & 71 & 28 & 54 \\
\hline Total & 35 & 100 & 17 & 100 & 52 & 100 \\
\hline
\end{tabular}

Table 3: Presenting complains.

\begin{tabular}{|lllllll|}
\hline Complains & Male n & Male $\%$ & Female & Female $\%$ & Total $n$ & Total \% \\
\hline Skin rash & 12 & 13 & 16 & 26 & 23 & 15 \\
\hline Itching & 10 & 11 & 14 & 22 & 20 & 13 \\
\hline Vomiting & 3 & 3 & 3 & 5 & 3 & 2 \\
\hline Diarrhoea & 12 & 13 & 5 & 8 & 14 & 9 \\
\hline Gastric bleeding & 4 & 4 & 2 & 3 & 6 & 4 \\
\hline Abdominal pain & 8 & 9 & 2 & 3 & 10 & 8 \\
\hline Constipation & 1 & 1 & 1 & 2 & 1 & 1 \\
\hline Cough & 1 & 1 & 2 & 3 & 3 & 2 \\
\hline Sweating & 6 & 7 & 2 & 3 & 8 & 5 \\
\hline Drowsiness & 6 & 7 & 2 & 3 & 8 & 5 \\
\hline Weakness & 6 & 7 & 2 & 3 & 8 & 5 \\
\hline Seizure & 1 & 1 & 1 & 2 & 2 & 1 \\
\hline Abnormal lab findings & 2 & 2 & 4 & 6 & 6 & 4 \\
\hline Peripheral neuropathy & 1 & 1 & 1 & 2 & 2 & 1 \\
\hline Sedation & 3 & 4 & 0 & 0 & 3 & 2 \\
\hline Headache & 1 & 1 & 1 & 2 & 2 & 3 \\
\hline Discolouration of sclera & 5 & 5 & 0 & 0 & 5 & 2 \\
\hline Hypotension & 1 & 1 & 2 & 3 & 3 & 2 \\
\hline Palpitations & 1 & 1 & 1 & 2 & 2 & 1 \\
\hline Breathlessness & 2 & 2 & 1 & 2 & 3 & 1 \\
\hline Abdominal fullness & 1 & 1 & 1 & 2 & 2 & 1 \\
\hline Joint pain & 1 & 1 & 1 & 2 & 2 & 1 \\
\hline Weight gain & 1 & 1 & 0 & 0 & & 2 \\
\hline
\end{tabular}


Table 1 shows type of patients who develop ADRs, either were outpatients or inpatients. Total 52 patients were outpatients who developed ADRs. While remaining 48 patients were inpatients who developed ADRs. This result was in consistence with the earlier documented study. $^{18}$

Table 4: Organ systems involve.

\begin{tabular}{|c|c|c|c|c|c|c|}
\hline Organ system involve & Male n & Male \% & Female $\mathbf{n}$ & Female $\%$ & Total n & Total \% \\
\hline Skin & 17 & 19 & 26 & 42 & 43 & 28 \\
\hline Gastrointestinal & 25 & 27 & 12 & 19 & 37 & 24 \\
\hline Cardiovascular & 7 & 8 & 5 & 8 & 12 & 8 \\
\hline Central nervous & 6 & 7 & 2 & 3 & 8 & 5 \\
\hline Hypoglycaemic & 18 & 19 & 6 & 10 & 24 & 16 \\
\hline Musculoskeletal & 2 & 2 & 1 & 2 & 3 & 2 \\
\hline Metabolic & 1 & 1 & 3 & 5 & 4 & 3 \\
\hline Hepatobiliary & 6 & 7 & 0 & 0 & 6 & 4 \\
\hline Respiratory & 1 & 1 & 2 & 3 & 3 & 2 \\
\hline Others & 8 & 9 & 5 & 8 & 13 & 8 \\
\hline Total & 91 & 100 & 62 & 100 & 153 & 100 \\
\hline
\end{tabular}

Table 5: If reported by health care professionals.

\begin{tabular}{|lll|}
\hline Health care professionals & n & $\%$ \\
\hline Senior doctors/Physicians & 5 & 5 \\
\hline Post graduates & 61 & 61 \\
\hline Interns & 20 & 20 \\
\hline Nursing staffs & 10 & 10 \\
\hline Medical students & 4 & 4 \\
\hline Total & 100 & 100 \\
\hline
\end{tabular}

Table 6: Cause of ADR.

\begin{tabular}{|lcc|}
\hline Single drug & $\mathbf{7 6}$ & $\mathbf{7 6 \%}$ \\
\hline $\begin{array}{l}\text { Suspected drug } \\
\text { combinations/drug interaction }\end{array}$ & 24 & $24 \%$ \\
\hline Total & 100 & $100 \%$ \\
\hline
\end{tabular}

Table 2 shows that out of 52 outpatients who developed ADRs 24 of them were admitted (46\%) while remaining $(n=28,54 \%)$ were not admitted as ADRs in those patients were not serious. So from the table above we can say that ADR related hospital admission and ADRs during the hospital stay is significantly high. This result was in consistence with the earlier documented study. ${ }^{17-19}$

Table 3 shows presenting complain in each patient due to suspected ADRs and Table 4 shows how those presenting complains has been kept under various organ system classification with gender distribution. The most common presenting complains is skin rash and itching followed by diarrhoea. The commonest organ system involved in ADRs were skin accounting for $(n=43,28 \%)$ of total ADRs which is consistent with previous studies that dermatological manifestation of ADR are common. ${ }^{20,21}$
This is followed by involvement of gastrointestinal symptoms $(\mathrm{n}=37,24 \%)$.

We classified ADRs encountered based on Thompsons and Rawlins classification into Type A and Type B ADRs. It was observed that out of 100 cases 70 cases showed Type A ADRs while remaining 30 cases showed Type B ADRs. This pattern of different type of ADRs observed during the present study were similar to the observations of the earlier studies which had also reported higher incidences of Type A ADRs. ${ }^{22,23}$

We also studied type of prescription involved in ADRs. In the present study majority of the cases who encountered ADR took doctor's prescription ( $n=92,92 \%)$ while remaining cases $(n=8,8 \%)$ took self-prescription on the basis of their previous visit and previous exposure to drug and due to lack of time to go to a doctor.

We also studied type of reporting of ADRs. In the present study all cases $(n=100,100 \%)$ of suspected ADRs were reported by health care professionals. There was no spontaneous reporting by the patients.

Table 5 shows maximum reporting of ADRs among the health care professionals were from post graduates $(n=61$, $61 \%)$ and medical students contributed the least $(n=4$, $4 \%$ ). This was further correlated by chart review of the patients especially inpatients. The pattern of reporting of the present study were similar to the observation of the previous studies were the active participation of health care professionals can really increase the ADRs reporting. ${ }^{13,20,24}$

Table 6 shows total no of cases $(n=76)$ were suspected ADRs is due to one drug. While remaining 24 cases, 
ADR was due to fixed dose combinations or suspected drug interactions.

Table 7 shows that in 76 cases single drug was the cause of ADR. Majority of ADRs were caused due to antimicrobials $(\mathrm{n}=33,43 \%)$ Amoxicillin + Clavulanic acid followed by Ceftriaxone which were consistent with previous studies probably because they are most commonly prescribed drugs in our hospital setting. ${ }^{21,25}$

Table 7: 76 cases who had adverse drug reaction with only one drug.

\begin{tabular}{|c|c|c|c|c|c|c|}
\hline Class of drugs & Male $\mathbf{n}$ & Male \% & Female $\mathbf{n}$ & Female $\%$ & Total n & Total \% \\
\hline Antibacterial & 17 & 41 & 16 & 45 & 33 & 43 \\
\hline Antitubercular & 3 & 7 & 3 & 9 & 6 & 7 \\
\hline Cardiovascular & 5 & 13 & 3 & 9 & 8 & 10 \\
\hline Antiepileptics & 4 & 10 & 1 & 2 & 5 & 7 \\
\hline NSAID's & 2 & 5 & 3 & 9 & 5 & 7 \\
\hline Diuretics & 2 & 5 & 3 & 9 & 5 & 7 \\
\hline Brochodilators & 1 & 2 & 0 & 0 & 1 & 1 \\
\hline Corticosteroids & 2 & 5 & 1 & 2 & 3 & 4 \\
\hline Hypogylcaemics & 3 & 7 & 2 & 6 & 5 & 7 \\
\hline Others ${ }^{*}$ & 2 & 5 & 3 & 9 & 5 & 7 \\
\hline Total & 41 & 100 & 35 & 100 & 76 & 100 \\
\hline
\end{tabular}

* Drugs were Ondansetron, Ferrous fumarate,Tramadol, Diazepam and Promethazine.

Table 8: ADR due to drug combinations/suspected drug interactions.

\begin{tabular}{|lll|}
\hline Drug combinations/Drug interactions & No of cases & Presenting complains \\
\hline Isoniazid + Rifampicin + Pyrazinamide & 2 & Jaundice \\
\hline Paracetamol + Diclofenac & 2 & Upper git bleeding \\
\hline Zidovudine+ Lamivudine+ Nevirapine & 1 & Pallor \\
\hline Zidovudine+ Lamivudine+ Nevirapine & 1 & Headache and insomnia \\
\hline Zidovudine+ Lamivudine+Efavirenz & 1 & Jaundice \\
\hline Glimepiride+Insulin & 3 & Sweating, drowsiness \\
\hline Glipizide+Insulin & 1 & Sweating, drowsiness and weakness \\
\hline Sitagliptin+Glimepiride & 1 & Sweating, drowsiness and weakness \\
\hline Aspirin and clopidogrel & 1 & Haematuria \\
\hline Aspirin and clopidogrel & 1 & Upper git bleeding \\
\hline Aspirin and clopidogrel & 1 & Black tarry stools and abdominal pain \\
\hline Valproate + Atorvastatin & 1 & Jaundice \\
\hline Azithromycin +Paracetamol & 1 & diarrhoea \\
\hline Diazepam +Alcohol & 1 & sedation \\
\hline Ramipril+ Spironolactone & 1 & palpitations \\
\hline Ramipril + Aspirin & 1 & hypertension \\
\hline Methylprednisolone + Levofloxacin & 1 & hyperglycaemia \\
\hline Hydrocortisone + Levofloxacin & 1 & hyperglycaemia \\
\hline Norfloxacin + Metronidazole & 1 & Itching all over the body \\
\hline Furosemide+ Spironolactone & 1 & Hyponatremia \\
\hline Total no of cases & 24 & \\
\hline
\end{tabular}

Table 8 shows remaining 24 cases were the cause of suspected ADRs was either fixed dose combinations or suspected drug interactions.
We also studied the final outcome of the suspected drug as a whole. Out of total 100 cases in 52 cases the suspected drug was withdrawn and alternate therapy was 
implemented. This observation of the present study result were similar to the observation of the past studies. ${ }^{13,17}$

Treatment of ADRs as a whole was also studied. Out of 100 cases total of $(\mathrm{n}=72,72 \%)$ cases required symptomatic treatment This observation of the present study were similar to the observation of the past studies. $^{13,17}$

Table 9: Final Outcome of the suspected ADRs.

\begin{tabular}{|lllllll|}
\hline Outcome & Male $\mathbf{n}$ & Male \% & Female n & Female \% & Total n & Total \% \\
\hline Recovered & 40 & 66 & 27 & 69 & 67 & 67 \\
\hline Recovering & 12 & 20 & 7 & 18 & 19 & 19 \\
\hline Continue & 4 & 6 & 1 & 3 & 5 & 5 \\
\hline Loss to follow up & 5 & 8 & 4 & 10 & 9 & 9 \\
\hline Deaths & 0 & 0 & 0 & 0 & 0 & 0 \\
\hline Others & 0 & 0 & 0 & 0 & 0 & 0 \\
\hline Total & 61 & 100 & 39 & 100 & 100 & 100 \\
\hline
\end{tabular}

Table 10: WHO UMC causality assessment criteria.

\begin{tabular}{|lllllll|}
\hline WHO UMC causality & Male $\mathbf{n}$ & Male \% & Female n & Female \% & Total n & Total \% \\
\hline Certain & 6 & 10 & 4 & 10 & 10 & 10 \\
\hline Probable & 41 & 67 & 27 & 69 & 68 & 68 \\
\hline Possible & 14 & 23 & 8 & 21 & 22 & 22 \\
\hline Unlikely & 0 & 0 & 0 & 0 & 0 & 0 \\
\hline Conditional & 0 & 0 & 0 & 0 & 0 & 0 \\
\hline Unassessable & 0 & 0 & 0 & 0 & 0 & 0 \\
\hline Total & 61 & 100 & 39 & 100 & 100 & 100 \\
\hline
\end{tabular}

Table 11: Adapted Hartwig severity scale.

\begin{tabular}{|lllllll|}
\hline Adapted Hartwig severity & Male n & Male \% & Female n & Female \% & Total n & Total \% \\
\hline Mild & 14 & 22 & 5 & 13 & 19 & 19 \\
\hline Moderate & 40 & 65 & 28 & 72 & 68 & 68 \\
\hline Severe & 7 & 13 & 6 & 15 & 13 & 13 \\
\hline Total & 61 & 100 & 39 & 100 & 100 & 100 \\
\hline
\end{tabular}

Table 12: Schumock and Thornton preventability assessment criteria.

\begin{tabular}{|lllllll|}
\hline Schumock and Thornton & Male $\mathbf{n}$ & Male \% & Female $\mathbf{n}$ & Female \% & Total n & Total \% \\
\hline Definitely preventable & 5 & 8 & 5 & 13 & 10 & 10 \\
\hline Probable preventable & 37 & 61 & 28 & 72 & 65 & 65 \\
\hline Not preventable & 19 & 31 & 6 & 15 & 25 & 25 \\
\hline Total & 61 & 100 & 39 & 100 & 100 & 100 \\
\hline
\end{tabular}

Table 9 shows outcome due to ADRs in which total of $(n=67,67 \%)$ cases recovered. The result of the present study were similar to the results of the past studies. ${ }^{13,17,26}$
Table 10 shows WHO UMC causality assessment criteria which shows total majority of the reported ADRs were evaluated as being probable, $(n=68,68 \%)$. The result of 
the present study were similar to the results of the past studies. $^{19,27}$

Table 11 shows assessment of severity of ADR based on Adapted Hartwig severity scale which shows total majority of ADRs $(n=68,68 \%)$ were categorized as moderately severe which were similar to the findings of previous studies. $^{28}$

Table 12 summarizes about the preventability of suspected ADRs as assessed by Modified Schumock And Thornton Criteria, it revealed that total $(n=65,65 \%)$ of ADRs were probably preventable which was in accordance with previous studies. ${ }^{28}$

Total cost incurred during the management of ADRs is Rs 92650.30 which was almost approximately close to the observations in the past studies. ${ }^{28}$ Here for 48 inpatients the mean cost for the management of these cases were Rs 368.48 which was approximately similar to the observation of the past studies. ${ }^{25} 28$ patients who visited the OPD but were not admitted, the mean cost incurred by them were Rs 145.50. Remaining 24 cases who were admitted due to Adr. The mean cost incurred by them was Rs 2943.35 .

\section{CONCLUSION}

Hospital based ADR monitoring and reporting programmes aim to identify and quantify the risks associated with the use of the drugs.

This information may be useful in identifying and minimizing the preventable ADRs while enhancing the knowledge of the prescribers to deal with ADRs more efficiently.

Pharmacovigilance programmes have been introduced in India but it still appears to be in its primitive stage.

The total cost of Rs 92650.30 incurred in the management of total no of ADRs encountered during the study underlines the fact that ADRs pose an extra financial burden to the patients.

Regular training programmes by the way of workshop and seminars must be carried out for health care professionals to increase the awareness about ADR reporting.

\section{Funding: No funding sources}

Conflict of interest: None declared

Ethical approval: The study was approved by the Institutional Ethics Committee

\section{REFERENCES}

1. Jacoline C, Marie L, Mare A. Epidemiology of ADRs in Europe. A review of recent observational studies. Springer. 2015;38(5).
2. Vishal R. Tandon, Vijay K, Annil M, Zahid Gi, Vivek M, and Vijant $\mathrm{C}$ Fatal adverse drug reactions Experience of adverse drug reactions in a tertiary care teaching hospital of North India- A case series. Indian J Crit Care Med. 2014;18(5):315-9.

3. Rao PGM, Archana B, Jose J. Implementation and results of an ADR reporting programme at an Indian teaching hospital. Indian Journal of Pharmacology. 2006;38(4):293-4.

4. Rabbur RSM, Emmerton L. An introduction to adverse drug reporting system in different countries. Intl J Pharm Prac. 2005;13(1):91-100.

5. Sriram S, Ghasemi A, Ramasamy R, Devi M, Balasubramanian R, Ravia TK. Prevalence of ADRs at a private tertiary care hospital in south India. Journal of Research in Medical Sciences. 2011;16(1):16-25.

6. Vora MB, Trivedi HR, Shah BK, Tripathi CB. ADRs in inpatients of internal medicine ward at a tertiary care hospital: A prospective cohort study. Journal of Pharmacology and Pharmacotherapeutics. 2011;2(1):21-5.

7. Rahmawati F, Pramantara DP. ADRs (ADRs) in geriatric hospitalized patients. Majalah Farmasi Indonesia. 2008;19(4):185-90.

8. Hazell L, Shakir SAW. Under-reporting of adverse drug reactions: a systematic review. Drug Saf. 2006;29:385-96.

9. McGettigan P, Golden J, Conroy RM, Arthur N, Feely J. Reporting of adverse drug reactions by hospital doctors and the response to intervention. $\mathrm{Br} \mathrm{J}$ Clin Pharmacol. 1997;44:98-100.

10. Padmaja U, Adhikari P, Pereira P. A Prospective Analysis of ADRs in a South Indian Hospital. Online Journal of Health Allied Sciences. 2009;8(3):12.

11. Singh H, Dulhani N, Kumar BN, Singh P, Tewari P, Nayak K. A Pharmacovigilance Study in Medicine Department of Tertiary Care Hospital in Chhattisgarh (Jagdalpur), India. General Pharmacy. 2010;2(1):95100 .

12. Pirmohamed M, James S, Meakin S, Green C, Scott AK, Walley TJ, Farrar K. ADRs as cause of admission to hospital: Prospective analysis of 18820 patients. BMJ. 2004;329:15-9.

13. Palanisamy S, Kumaran AK, Rajasekaran A. A study on assessment, monitoring, documentation and reporting of adverse drug reaction at a multi-specialty tertiary care hospital in South India. Int J Pharmatech Res. 2009;1(4):1519-1522.

14. Munir P, Sally J and Shaun M. Adverse drug reaction as cause of admissions to hospital: Prospective analysis of 18820 patients. British Medical Journal. 2004:329-15.

15. Kongaew C.A prospective observational study on the prevalence of adverse drug reaction. British Medical journal. 2010:23-25.

16. Gonzalez EL, Herderio MT, Figueiras A. Determinants of under-reporting of adverse drug reaction a systematic review. Drug Saf. 2009;32(1):19-31 
17. Mukeshkumar B, Vora, Hiren R. Adverse drug reactions in inpatients of internal medicine wards at a tertiary care hospital. A prospective cohort study. J pharmacol pharmacother. 2011;2(1):21-5.

18. Arulmani R, Rajendran SD, and Suresh B. Adverse drug reaction monitoring in a secondary care hospital in South India. Br J Clinpharmacol. 2008;:65(2):2106.

19. Cornelis S, Jeanne PD, Claire S. Adverse drug reaction related hospitalizations: A population based cohort study. Pharmacoepidemiology and Drug safety. 2008:365-371.

20. Li XY. To investigate the occurrences and features of adverse drug reaction. Journal of Harbin Medical Unit; 2010:01-026.

21. Jha N, Bajracharya O, Namgyal T. Prevalence of adverse drug reactions (ADRs) with the commonly prescribed drugs in different hospitals of Kathmandu valley. Kathmandu University Medica Journal. 2007;5(4):504-10.

22. Edward IR, Aronson JK. Adverse drug reaction: definition, diagnosis and management. Lancet. 2000;356(9237):1255-9.
23. Fracas A, Bojita M. Adverse drug reaction in clinical practice: a causality assessment of a case of druginduced pancreatitis. J Gastrointestin Liver Dis. 2009;18(3):353-8.

24. Karyn M, Sullivan, Linda MS. Adverse drug reaction reporting by pharmacy students in a teaching hospital. American Journal of Health-System Pharmacy. 2008;65:1177-9.

25. Khotaei GT. Adverse reactions to antibiotics in hospitalized Iranian children, J Microbiolo Immunol Infect. 2008;41:160-4.

26. Gor AP, Desai SV. Adverse drug reaction in the inpatients of Medicine Department of a rural tertiary care teaching hospital and influence of pharmacovigilance in reporting ADR. Indian $\mathbf{J}$ Pharmacol. 2008;40(1):37-40.

27. Arulmani R, Rajendran SD, Suresh B. Adverse drug reaction monitoring in a secondary care hospital in South India. Br J Clinpharmacol. 2008;65(2):210-6.

28. Ramesh M. Adverse drug reactions in a South Indian hospital-their severity and cost involved. Pharmaco epidemiology and Drug safety. 2003;5(4):669-75.

Cite this article as: Mishra R, Jeevangi SK,

Vardhamane S, Kumar S. Pharmacovigilance study in medicine department in a tertiary care hospital. Int J Basic Clin Pharmacol 2016;5:2608-15. 